\title{
Quantitative Analysis of the Vascular and Neural Compartments of the Jugular Foramen in Dry Skulls
}

\author{
Vural HAMZAOGLU ${ }^{1}$, Hakan OZALP ${ }^{1}$, Orhan BEGER ${ }^{2}$, Osman ERDOGAN ${ }^{3}$, Engin KARA ${ }^{4}$, Yusuf VAYISOGLU³ \\ Gulden KAYAN ${ }^{2}$, Alev BOBUS ${ }^{2}$, Ahmet DAGTEKIN ${ }^{1}$, Celal BAGDATOGLU ${ }^{1}$, Derya Umit TALAS ${ }^{3}$
}

\author{
${ }^{1}$ Mersin University, Faculty of Medicine, Department of Neurosurgery, Mersin, Turkey \\ ${ }^{2}$ Mersin University, Faculty of Medicine, Department of Anatomy, Mersin, Turkey \\ ${ }^{3}$ Mersin University, Faculty of Medicine, Department of Otorhinolaryngology, Mersin, Turkey \\ ${ }^{4}$ Mersin University, Faculty of Medicine, Department of Radiology, Mersin, Turkey \\ This study has been presented at the $1^{\text {st }}$ International Mediterranean Anatomy Congress between 6 and 9 September 2018 at Konya, Turkey.
}

Corresponding author: Orhan BEGER obeger@gmail.com

\section{ABSTRACT}

AIM: To compare the right and left sides and the endo-exocranial orifices of the jugular foramen (JF) considering the vascular compartment (VC) and the neural compartment (NC).

MATERIAL and METHODS: A total of 20 human dry skulls belonging to the inventory of Medical Faculty, Department of Anatomy, were included in this study. Numerical values were obtained using direct anatomical and also computed tomography measurements.

RESULTS: The endocranial and exocranial VC occupied wider areas on the right side than on the left side ( $p<0.05)$. However, there was no statistically significant difference between the surface area of the endocranial and exocranial NC in terms of the sides $(p>0.05)$. The length of the endocranial VC was greater on the right than on the left side. The right exocranial VC was wider than the left exocranial VC. However, the widths and lengths of the endocranial and exocranial NC showed no statistically significant difference between the sides ( $p>0.05)$.

CONCLUSION: The right-sided dominance of JF observed in this study was attributed to the length of endocranial VC and the width of exocranial VC.

KEYWORDS: Vascular compartment, Neural compartment, Jugular foramen, Sigmoid sinus

ABBREVIATIONS: JF: Jugular foramen, VC: Vascular compartment, NC: Neural compartment

\section{INTRODUCTION}

$\mathrm{T}$ The jugular foramen (JF), which transmits the inferior petrosal sinus, the jugular vein, the posterior meningeal artery, and the glossopharyngeal, vagus, and spinal accessory nerves, is a depression between the occipital bone and the petrous pyramid of the temporal bone. It is divided into the vascular compartment (VC) and the neural compartment $(\mathrm{NC})$ via a fibrous or bony septum $(6,9)$. This foraminal region is the transition zone for the tympanic branch (Jacobson's nerve) of the glossopharyngeal nerve and the auricular branch (Arnold's nerve) of the vagus nerve $(6,9)$. In addition to its complex and important neurovascular architecture, the size of JF is important for otosurgeons, neurosurgeons, and radiologists to avoid iatrogenic injury during surgical approaches within the complex structure of the skull base (11-19). Since the dimensional anomalies of

\begin{tabular}{|c|c|c|c|c|c|}
\hline Vural HAMZAOGLU & (D) : 0000-0003-0249-7711 & Engin KARA & (D) : $0000-0002-5182-0506$ & Ahmet DAGTEKIN & (D) : 0000-0001-7368-6937 \\
\hline Hakan OZALP & (D) : 0000-0002-8234-8013 & Yusuf VAYISOGLU & (D) : 0000-0002-7132-1317 & Celal BAGDATOGLU & (1) : 0000-0002-4237-9288 \\
\hline Orhan BEGER & (1) : 0000-0002-4932-8758 & Gulden KAYAN & (D) : 0000-0002-0042-8803 & Derya Umit TALAS & (1) : :0000-0002-3402-9229 \\
\hline Osman ERDOGAN & (D) : $0000-0001-9384-7881$ & Alev BOBUS & (D) : 0000-0003-4026-5460 & & \\
\hline
\end{tabular}


the JF may be associated with tumors (e.g., paragangliomas, meningiomas, and neural sheath tumors) (26), and congenital malformations (e.g., Crouzon, Apert, and Muenke syndromes) $(7,10)$, its size is increasingly being considered as an important area of research interest (1-3,8,11-19,21-25). Furthermore, dimensional differences of JF, such as the length, width, and area, are also examined in terms of demographic data such as gender, side, race, and region (1-3,12,19,27).

Although there are plenty of numerical data on the size of JF in the literature (1-3,11-19,21-25), the existing inventory conducted on the morphometric assessment of the dimension of $\mathrm{VC}$ and $\mathrm{NC}$, including their areas, lengths, and widths, appears to be limited (9). Therefore, the primary aim of the present study was to examine the size of $\mathrm{VC}$ and $\mathrm{NC}$ both exocranially and endocranially.

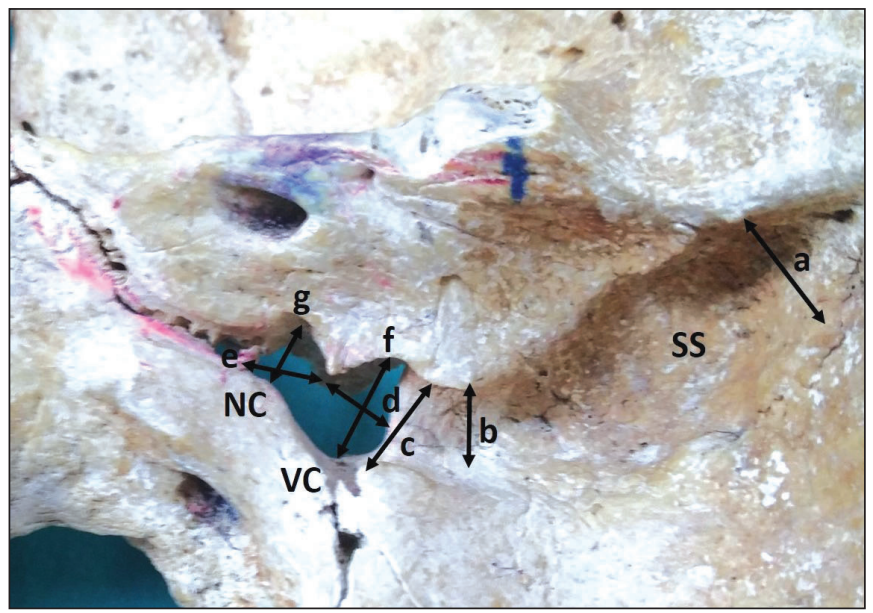

\section{MATERIAL and METHODS}

A total of 20 dry skulls with no deformities were included in this study, which was performed at the Department of Anatomy, Mersin University School of Medicine. The following parameters were measured (Figures 1,2):

The lengths and widths (the top level, the lowest level, and the most narrow level) of the sigmoid sinus

The total surface area, length, and width of the endocranial and exocranial JF

The surface area, length, and width of the endocranial and exocranial VC and NC

Length and width measurements were conducted using a digital caliper (MARCAL 16 ER, Mahr, Gottingen, Germany) (0.01 $\mathrm{mm}$ precision). Direct anatomical measurements (DAM)

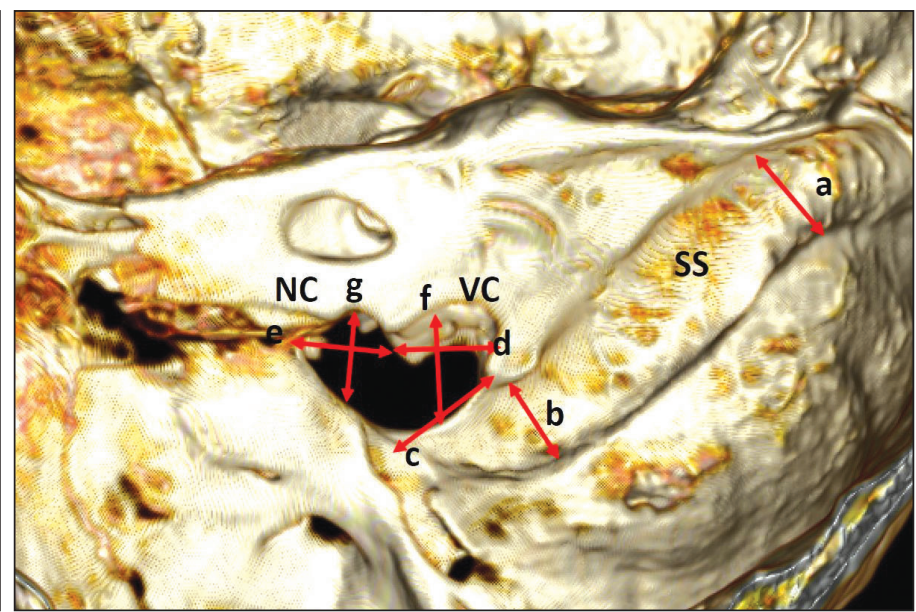

Figure 1: a) Widths of the top level of the sigmoid sinus (SS), b) widths of the most narrow level of the SS, c) widths of the lowest level of the SS, d) the length of the endocranial VC, e) the length of the endocranial NC, f) the width of the endocranial VC, and $\mathbf{g}$ ) the width of the endocranial NC.
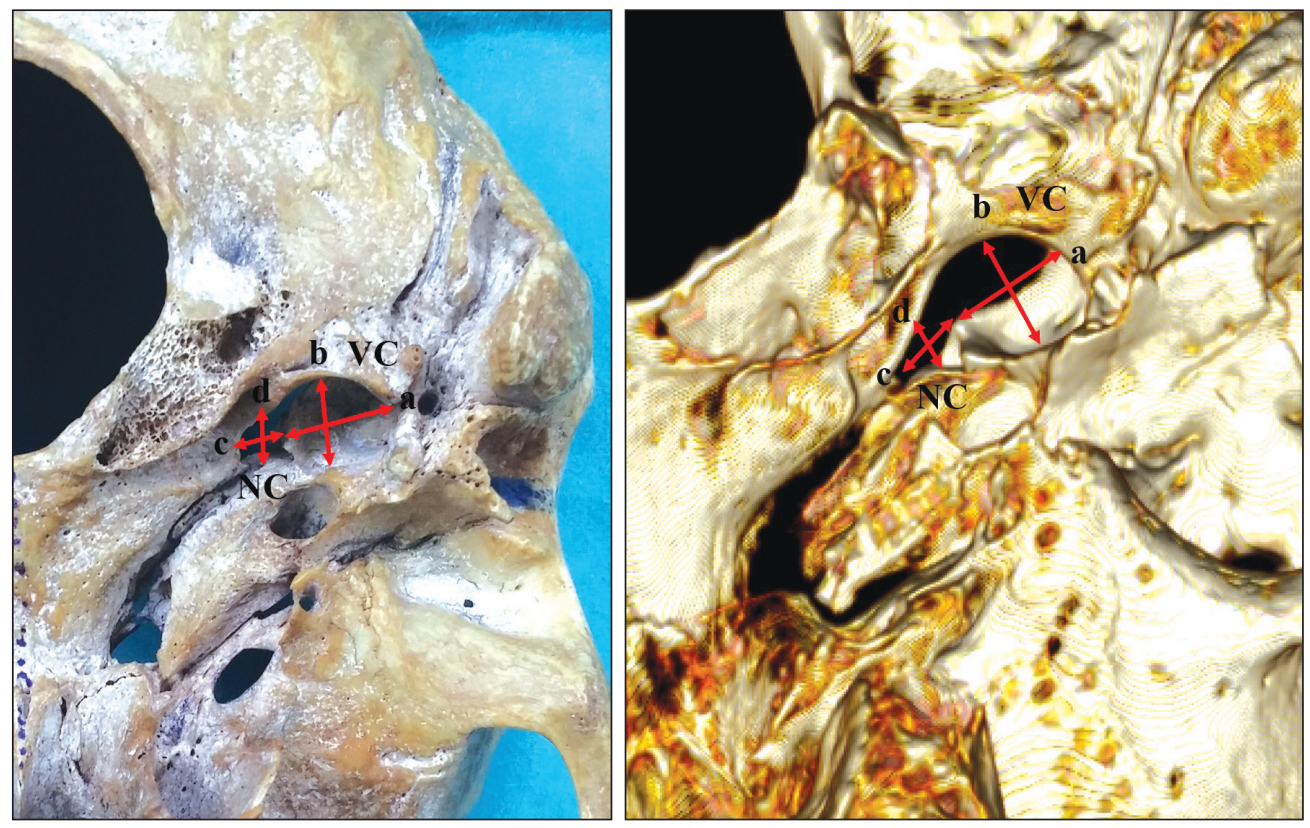

Figure 2: a) The length of the exocranial $\mathrm{VC}, \mathbf{b})$ the width of the exocranial VC, c) the length of the exocranial $\mathrm{NC}$, and $\mathrm{d}$ ) the width of the exocranial NC. 
were performed by the same researcher (GK). Under the same position with a millimeter scale, the VC and NC of JF were captured (LG), and then their surface areas were calculated using a digital image analysis program (Rasband WS, ImageJ, U. S. National Institutes of Health, Bethesda, MD, https:// imagej.nih.gov/ij/, 1997-2018). In the axial, coronal, and sagittal planes using $0.5-\mathrm{mm}$-thin sections skull algorithm, the raw data were reformatted and then three-dimensional images were created at the workstation (Vitrae 2). A senior radiologist $(E K)$ evaluated the computed tomography (CT) data obtained from a 64-slice scanner (Aquillion 64, Toshiba Medical Systems Tokyo, Japan).

\section{Statistical Analysis}

Normality of the data sets was assessed using the ShapiroWilk test. Variance homogeneity was evaluated using the Levene test. Comparisons between the sides (right and left) or between different measurement techniques (DAM and CT) were performed using the paired sample t-test. The correlations between the surface area, length, and width of the endocranial and exocranial VC and NC in DAM and CT were evaluated using the Pearson correlation coefficient test. The paired sample t-test was also used for comparisons among the surface area, length, and width of the endocranial and exocranial JF, VC, and NC. This test was further used to compare the width of the sigmoid sinus and the endocranial VC. ANOVA with repeated measures and Bonferroni tests were applied for comparisons of the three widths of the sigmoid sinus. The threshold for statistical significance was set as $p<0.05$. An interactive biostatistics software was used (www.e-picos.com, NewYork, NY) for the statistical analysis.

\section{RESULTS}

The mean and standard deviation values of the parameters obtained from CT and DAM are presented in Tables I and II. The correlations between the surface area, length, and width of the endocranial and exocranial VC and NC are shown in Tables III and IV. The outcomes of our study are described as follows:

- The lowest width of the sigmoid sinus in DAM and CT was wider on the right side than on the left side (Table I).

- The length of the endocranial VC in DAM and CT was greater on the right side than on the left side (Table II). The right exocranial VC was wider than the left exocranial VC (Table II).

- The endocranial and exocranial VC in DAM and CT had wider areas on the right side than on the left side. However, there was no statistically significant difference between the surface areas of the endocranial and exocranial $\mathrm{NC}$ in DAM and CT in terms of the sides.

- In DAM, positive correlations were found between the length and width of the endocranial VC $(p<0.001, r=0.532)$, between the width of the endocranial and exocranial VC $(p=0.003, r=0.462)$, and between the length of the endocranial and exocranial NC $(p=0.01, r=0.387)$ (Table III). Furthermore, positive correlations were found between

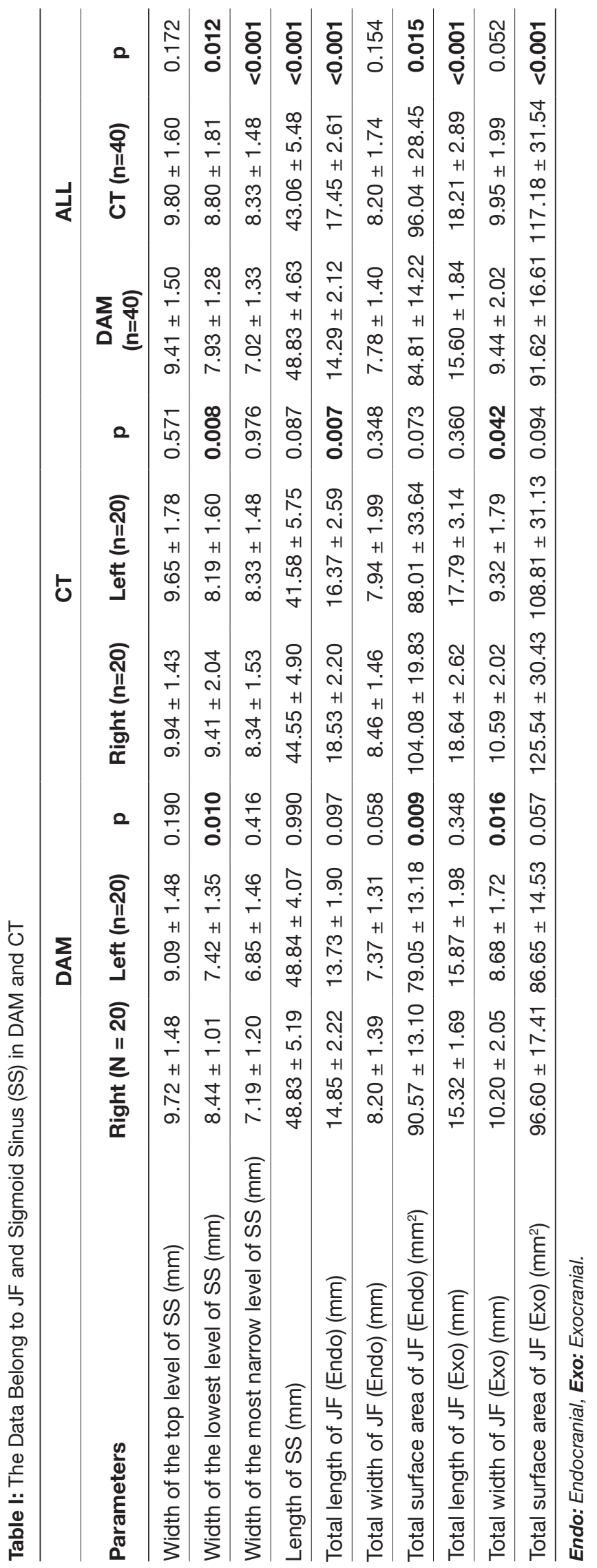




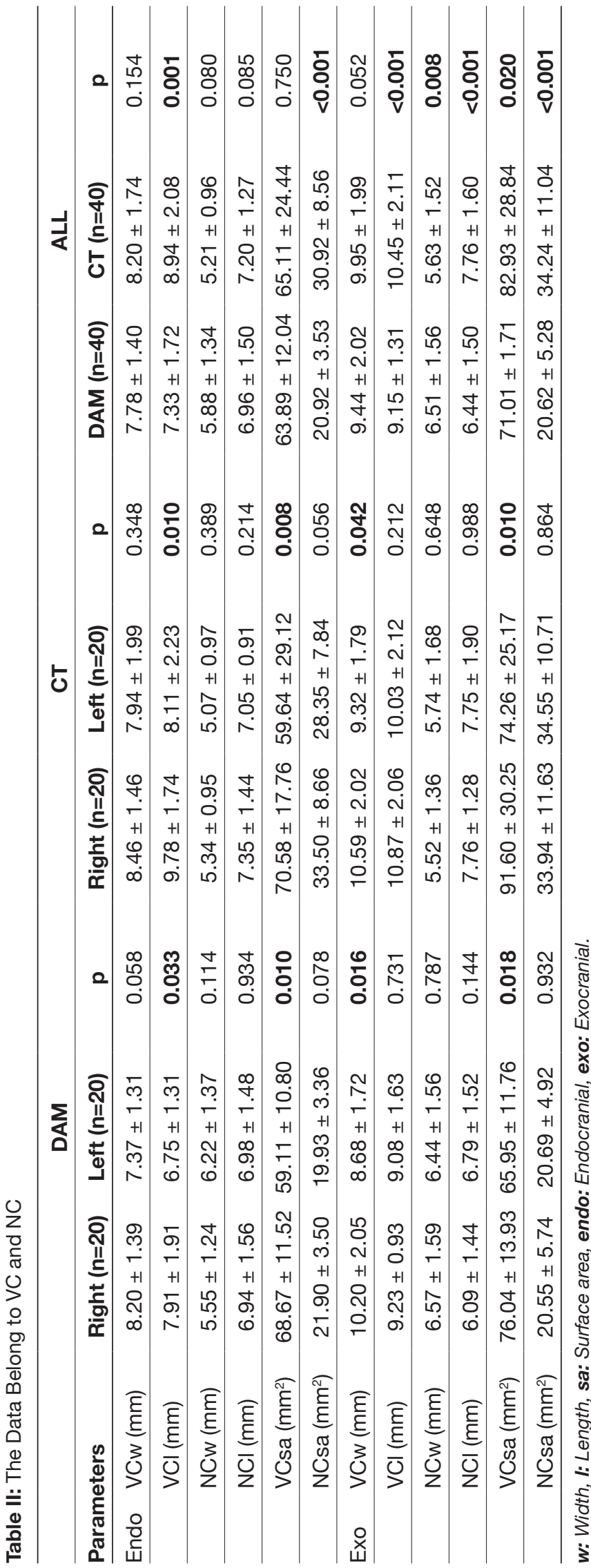

both the surface areas of the endocranial $\mathrm{VC}$ and $\mathrm{NC}$ $(p<0.001, r=0.526)$ and the surface areas of the exocranial VC and NC ( $p=0.008, r=0.414)$ (Table IV).

- In CT, positive correlations were found between the length and width of the endocranial VC $(p=0.017, r=0.377)$, between the width of the endocranial VC and the length of the exocranial VC $(p=0.012, r=0.393)$, and between the length and width of the exocranial VC $(p=0.018, r=0.374)$ (Table III). Positive correlations were also observed between the surface areas of the endocranial VC and NC $(p=0.037, r=0.331)$ and between the surface areas of the endocranial and exocranial VC $(p=0.010, r=0.400)$ (Table IV).

- The exocranial VC was wider and longer than the endocranial VC in DAM and CT $(p<0.001)$. The exocranial $\mathrm{NC}$ was partly wider than the endocranial $\mathrm{NC}(\mathrm{p}=0.03)$; however, there was no statistically significant difference between their lengths $(p=0.058)$. In $C T$, the length and width of the endocranial and exocranial NC showed no statistically significant difference ( $p>0.05$ ) (Table V).

- In DAM, there was no significant difference between the length and width of the exocranial VC ( $p>0.05)$, but the CT data revealed that the length of the exocranial NC was greater than its width. The exocranial VC was wider and longer than the exocranial NC in both DAM and CT $(p<0.001)$ (Table V).

- In DAM and CT, no difference was found between the length and width of the endocranial VC. However, the length of the endocranial NC in both DAM and CT was greater than its width $(p<0.001)$. The length of the endocranial VC and $\mathrm{NC}$ in DAM showed no statistically significant variation $(p=0.342)$, but the CT findings demonstrated that the endocranial VC was longer than the endocranial NC. The endocranial VC was also wider than the endocranial NC in both DAM and CT $(\mathrm{p}<0.001)$ (Table V).

- The endocranial and exocranial VC in DAM and CT showed a wider area than NC $(p<0.001)$. The surface area of the exocranial VC in DAM and CT was larger than that of endocranial VC. However, no statistically significant difference was found between their surface areas of NC in both DAM and CT ( $p=0.753)$ (Table V).

- The right endocranial VC was longer in $70 \%$, the left endocranial VC was longer in $20 \%$, and it was equal on both sides in $10 \%$, whereas it was wider in $45 \%$, the left endocranial VC was wider in $20 \%$, and it was equal on each side in $35 \%$. In addition, it had a larger area in $80 \%$, and the left endocranial VC was larger in $20 \%$.

- The right endocranial NC was longer in 35\%, the left endocranial NC was longer in $30 \%$, and it was equal on both sides in $35 \%$, whereas the right endocranial NC was wider in $15 \%$, the left endocranial NC was wider in $40 \%$, and it was equal on each side in $45 \%$. In addition, on the right side, it had a larger area in 50\%; the left endocranial $\mathrm{NC}$ was larger in $40 \%$, and it was equal on each side in $10 \%$. 
Table III: The Correlations Between the Length and width of Endocranial (Endo) and Exocranial (exo) VC and NC

\begin{tabular}{|c|c|c|c|c|c|c|c|c|c|c|c|c|c|c|c|}
\hline & & \multicolumn{7}{|c|}{ DAM } & \multicolumn{7}{|c|}{ CT } \\
\hline & & \multicolumn{3}{|c|}{ Endo } & \multicolumn{4}{|c|}{ Exo } & \multicolumn{3}{|c|}{ Endo } & \multicolumn{4}{|c|}{ Exo } \\
\hline & & vCw & $\mathrm{NCl}$ & NCw & $\mathrm{VCl}$ & VCw & $\mathrm{NCl}$ & $\mathrm{NCw}$ & VCw & $\mathrm{NCl}$ & $\mathrm{NCw}$ & $\mathrm{VCl}$ & vCw & $\mathrm{NCl}$ & NCw \\
\hline \multirow[t]{8}{*}{ Endo } & $\mathrm{VCl}$ & $0.532^{\star \star}$ & $* \quad-0.144$ & -0.216 & 0.223 & 0.210 & -0.237 & 0.016 & $0.377^{*}$ & 0.167 & 0.233 & 0.282 & 0.274 & 0.304 & -0.056 \\
\hline & & $<0.001$ & 0.376 & 0.180 & 0.166 & 0.193 & 0.141 & 0.920 & 0.017 & 0.302 & 0.148 & 0.065 & 0.087 & 0.050 & 0.731 \\
\hline & VCw & & $1-0.114$ & 0.105 & 0.161 & $0.462^{* *}$ & -0.303 & 0.242 & 1 & -0.010 & 0.308 & $0.393^{*}$ & 0.195 & 0.197 & 0.310 \\
\hline & & & 0.485 & 0.519 & 0.321 & 0.003 & 0.056 & 0.132 & & 0.949 & 0.056 & 0.012 & 0.227 & 0.224 & 0.053 \\
\hline & $\mathrm{NCl}$ & & 1 & 0.300 & -0.102 & -0.015 & $0.387^{*}$ & -0.008 & & 1 & 0.243 & 0.148 & 0.050 & -0.093 & -0.227 \\
\hline & & & & 0.060 & 0.532 & 0.928 & 0.014 & 0.959 & & & 0.132 & 0.362 & 0.760 & 0.568 & 0.159 \\
\hline & $\mathrm{NCw}$ & & & 1 & -0.058 & 0.118 & 0.232 & 0.274 & & & 1 & 0.166 & -0.007 & 0.235 & -0.007 \\
\hline & & & & & 0.723 & 0.470 & 0.150 & 0.088 & & & & 0.305 & 0.968 & 0.145 & 0.966 \\
\hline \multirow[t]{6}{*}{ Exo } & $\mathrm{VCl}$ & & & & 1 & 0.099 & -0.150 & 0.212 & & & & 1 & $0.374^{*}$ & 0.198 & -0.046 \\
\hline & & & & & & 0.543 & 0.357 & 0.188 & & & & & 0.018 & 0.222 & 0.777 \\
\hline & VCw & & & & & 1 & -0.177 & 0.184 & & & & & 1 & 0.098 & 0.078 \\
\hline & & & & & & & 0.275 & 0.256 & & & & & & 0.547 & 0.631 \\
\hline & $\mathrm{NCl}$ & & & & & & & -0.022 & & & & & & & -0.045 \\
\hline & & & & & & & & 0.895 & & & & & & & 0.784 \\
\hline
\end{tabular}

w: Width, l: Length, *. Correlation is significant at the 0.05 level, **. Correlation is significant at the 0.01 level.

Table IV: The Correlations Between the Surface Areas of Endocranial and Exocranial VC and NC

\begin{tabular}{cccccccc}
\hline & \multicolumn{3}{c}{ DAM } & \multicolumn{3}{c}{ CT } \\
\hline & Endocranial & \multicolumn{2}{c}{ Exocranial } & Endocranial & \multicolumn{2}{c}{ Exocranial } \\
\hline Endocranial & NCsa & VCsa & NCsa & NCsa & VCsa & NCsa \\
\hline & VCsa & $0.526^{\star *}$ & 0.187 & -0.146 & $0.331^{*}$ & $0.400^{*}$ & 0.283 \\
\hline & & 0.001 & 0.248 & 0.370 & 0.037 & 0.010 & 0.077 \\
\hline & NCsa & 1 & 0.302 & 0.143 & 1 & 0.139 & -0.072 \\
\hline Exocranial & & 0.058 & 0.379 & & 0.393 & 0.661 \\
\hline & VCsa & & 1 & $0.414^{* *}$ & & 1 & 0.065 \\
\hline
\end{tabular}

sa: Surface area, **. Correlation is significant at the 0.01 level.

- The right exocranial VC was longer in $50 \%$, the left exocranial VC was longer in $30 \%$, and it was equal on both sides in $20 \%$, whereas the right exocranial VC was wider in $65 \%$ and the left exocranial VC was wider in $35 \%$. In addition, the right exocranial VC had a larger area in $65 \%$, the left exocranial VC was larger in $25 \%$, and it was equal on each side in $10 \%$.

- The right exocranial NC was longer in $25 \%$, the left exocranial NC was longer in $40 \%$, and it was equal on both sides in $35 \%$, whereas the right exocranial NC was wider in $50 \%$, the left exocranial NC was wider in $40 \%$, and it was equal on each side in $10 \%$. In addition, the right exocranial NC had a larger area in $45 \%$, the left exocranial NC was larger in $35 \%$, and it was equal on each side in $20 \%$.

- There was no statistical difference between the width of the lowest level of the sigmoid sinus and the width of the endocranial VC $(p=0.442)$.

- The endocranial VC was wider than the most narrow level of the sigmoid sinus $(p=0.001)$. 
Table V: The Comparison of Endocranial and Exocranial VC and NC

\begin{tabular}{|c|c|c|c|c|c|}
\hline \multirow{2}{*}{$\begin{array}{l}\text { DAM } \\
\text { Parameters }\end{array}$} & & \multirow[b]{2}{*}{$\mathbf{p}$} & \multicolumn{3}{|c|}{ CT } \\
\hline & & & & meters & p \\
\hline Endo VCl & Endo VCw & 0.068 & Endo VCI & Endo VCw & 0.052 \\
\hline Endo $\mathrm{NCl}$ & Endo NCw & $<0.001$ & Endo $\mathrm{NCl}$ & Endo NCw & $<0.001$ \\
\hline Endo VCl & Endo $\mathrm{NCl}$ & 0.342 & Endo VCl & Endo $\mathrm{NCl}$ & $<0.001$ \\
\hline Endo VCw & Endo NCw & $<0.001$ & Endo VCw & Endo NCw & $<0.001$ \\
\hline Exo VCl & Exo $\mathrm{NCl}$ & $<0.001$ & Exo VCl & Exo $\mathrm{NCl}$ & $<0.001$ \\
\hline Exo VCw & Exo NCw & $<0.001$ & Exo VCw & Exo NCw & $<0.001$ \\
\hline Exo VCl & Exo VCw & 0.440 & Exo VCl & Exo VCw & 0.181 \\
\hline Exo $\mathrm{NCl}$ & Exo NCw & 0.846 & Exo $\mathrm{NCl}$ & Exo NCw & $<0.001$ \\
\hline Endo VCl & Exo VCl & $<0.001$ & Endo VCl & Exo VCl & $<0.001$ \\
\hline Endo VCw & Exo VCw & $<0.001$ & Endo VCw & Exo VCw & $<0.001$ \\
\hline Endo $\mathrm{NCl}$ & Exo $\mathrm{NCl}$ & 0.058 & Endo $\mathrm{NCl}$ & Exo $\mathrm{NCl}$ & 0.454 \\
\hline Endo NCw & Exo NCw & 0.031 & Endo NCw & Exo NCw & 0.145 \\
\hline Endo VCsa & Endo NCsa & $<0.001$ & Endo VCsa & Endo NCsa & $<0.001$ \\
\hline Exo VCsa & Exo NCsa & $<0.001$ & Exo VCsa & Exo NCsa & $<0.001$ \\
\hline Endo VCsa & Exo VCsa & 0.009 & Endo VCsa & Exo VCsa & $<0.001$ \\
\hline Endo NCsa & Exo NCsa & 0.753 & Endo NCsa & Exo NCsa & 0.154 \\
\hline
\end{tabular}

w: Width, l: Length, sa: Surface area, endo: Endocranial, exo: Exocranial.

Table VI: The Comparison of the Data Belonging to JF with Previous Studies

\begin{tabular}{|c|c|c|c|c|c|c|c|c|c|c|}
\hline \multirow[b]{2}{*}{ Studies } & \multirow[b]{2}{*}{ Region } & \multirow{2}{*}{$\begin{array}{c}\mathbf{N} \text { of } \\
\text { Skulls }\end{array}$} & \multirow[b]{2}{*}{ Side } & \multirow[b]{2}{*}{ Part } & \multicolumn{3}{|c|}{ JF diameters } & \multicolumn{3}{|c|}{ Size of JF (\%) } \\
\hline & & & & & $\begin{array}{l}\text { Length (ML) } \\
\text { (mm) }\end{array}$ & $\begin{array}{c}\text { Width (AP) } \\
(\mathrm{mm})\end{array}$ & Area $\left(\mathrm{mm}^{2}\right)$ & $R>L$ & $L>R$ & $R=\mathbf{L}$ \\
\hline \multirow[t]{2}{*}{$\begin{array}{l}\text { Abhilasha et al. } \\
\text { (1) }\end{array}$} & India & 50 & $\mathrm{R}$ & - & $17.19 \pm 3.66$ & $6.68 \pm 1.99$ & $382.22 \pm 179.18$ & 65 & 25 & 10 \\
\hline & & & $\mathrm{L}$ & & $15.47 \pm 3.25$ & $5.78 \pm 2.07$ & $292.47 \pm 147.14$ & & & \\
\hline \multirow[t]{2}{*}{ Ahmed et al. (3) } & India & 100 & $\mathrm{R}$ & Exo & $14.66(9-16)$ & $9.88(6-13.5)$ & 99.18 & - & - & - \\
\hline & & & $\mathrm{L}$ & & $14.39(8.5-14)$ & $7.47(5-10)$ & 65.93 & & & \\
\hline \multirow[t]{4}{*}{ Das et al. (8) } & India & 114 & $\mathrm{R}$ & Endo & $13.25 \pm 1.56$ & $7.07 \pm 1.29$ & - & - & - & - \\
\hline & & & $\mathrm{L}$ & & $12.26 \pm 1.33$ & $5.51 \pm 2.25$ & - & & & \\
\hline & & & $\mathrm{R}$ & Exo & $13.72 \pm 2.70$ & $9.37 \pm 2.61$ & - & - & - & - \\
\hline & & & $\mathrm{L}$ & & $13.07 \pm 2.09$ & $6.88 \pm 1.72$ & - & & & \\
\hline \multirow[t]{4}{*}{$\underline{\text { Di Chiro et al. (9) }}$} & USA & 129 & $\mathrm{R}$ & Exo & $16.6(8-25)$ & $10.7(5-15)$ & - & 62.02 & 32.55 & 5.43 \\
\hline & & & $\mathrm{L}$ & & $16.2(6-21)$ & $9(4-16)$ & - & & & \\
\hline & & 70 & $\mathrm{R}$ & Endo & $14.5(7-20)$ & $8.2(5-14)$ & - & 55.72 & 37.14 & 7.14 \\
\hline & & & $\mathrm{L}$ & & $14.1(6-19)$ & $7.7(4-13)$ & - & & & \\
\hline \multirow[t]{2}{*}{ Gupta et al. (11) } & India & 50 & $\mathrm{R}$ & Exo & $16.52 \pm 2.03$ & $11.22 \pm 2.47$ & $187.34 \pm 55.62$ & - & - & - \\
\hline & & & $\mathrm{L}$ & & $16.02 \pm 2.20$ & $9.52 \pm 1.55$ & $153.20 \pm 35.80$ & & & \\
\hline $\begin{array}{l}\text { Hatiboğlu and } \\
\text { Anıl (12) }\end{array}$ & Turkey & 300 & - & - & - & - & - & 61.6 & 26 & 12.4 \\
\hline
\end{tabular}


Table VI: Cont.

\begin{tabular}{|c|c|c|c|c|c|c|c|c|c|c|}
\hline \multirow[b]{2}{*}{ Studies } & \multirow[b]{2}{*}{ Region } & \multirow[b]{2}{*}{$\begin{array}{l}\mathbf{N} \text { of } \\
\text { Skulls }\end{array}$} & \multirow[b]{2}{*}{ Side } & \multirow[b]{2}{*}{ Part } & \multicolumn{3}{|c|}{ JF diameters } & \multicolumn{3}{|c|}{ Size of JF (\%) } \\
\hline & & & & & $\begin{array}{l}\text { Length (ML) } \\
(\mathrm{mm})\end{array}$ & $\begin{array}{l}\text { Width (AP) } \\
(\mathrm{mm})\end{array}$ & Area $\left(\mathrm{mm}^{2}\right)$ & $R>L$ & $L>R$ & $\mathbf{R}=\mathbf{L}$ \\
\hline $\begin{array}{l}\text { Hussain Saheb } \\
\text { et al. (14) }\end{array}$ & India & 125 & $\mathrm{R}$ & - & $23.62 \pm 2.29$ & $7.83 \pm 1.36$ & $584.36 \pm 131.28$ & 64.8 & 24.8 & 10.4 \\
\hline \multirow[t]{2}{*}{ Idowu (15) } & Nigeria & 20 & $\mathrm{R}$ & - & $13.90 \pm 1.48$ & $10.22 \pm 2.67$ & $437.49 \pm 114.29$ & 55 & 25 & 20 \\
\hline & & & $\mathrm{L}$ & & $14.11 \pm 3.13$ & $9.57 \pm 1.84$ & $419.48 \pm 106.52$ & & & \\
\hline \multirow[t]{2}{*}{$\begin{array}{l}\text { Ishwarkumar et } \\
\text { al. (16) }\end{array}$} & South Africa & 73 & $\mathrm{R}$ & Exo & 12.89 & 6.43 & - & - & - & \\
\hline & & & $\mathrm{L}$ & & 12.12 & 5.39 & - & & & \\
\hline \multirow[t]{2}{*}{$\begin{array}{l}\text { Jain and } \\
\text { Kushwah (17) }\end{array}$} & India & 250 & $\mathrm{R}$ & Exo & $15.67 \pm 2.28$ & $9.32 \pm 2.04$ & - & 70 & 22 & 8 \\
\hline & & & $\mathrm{L}$ & & $14.85 \pm 2.89$ & $7.34 \pm 2.04$ & - & & & \\
\hline \multirow[t]{2}{*}{ Kumar et al. (18) } & India & 68 & $\mathrm{R}$ & Exo & $13.6(12-16.2)$ & 10.6 & - & 64.7 & 19.1 & 16.1 \\
\hline & & & $\mathrm{L}$ & & $13.9(11.9-16.5)$ & 9.2 & - & & & \\
\hline \multirow[t]{2}{*}{$\begin{array}{l}\text { Patel and Mehta } \\
(21)\end{array}$} & India & 100 & $\mathrm{R}$ & Exo & $12.17(4.5-16.5)$ & $7.9(3-12.5)$ & - & 75 & 23 & 2 \\
\hline & & & $\mathrm{L}$ & & $11(5-16)$ & $6.2(3-12.5)$ & - & & & \\
\hline \multirow[t]{2}{*}{ Pereira et al. (22) } & Brazil & 111 & $\mathrm{R}$ & Exo & $15.82 \pm 2.67$ & $9.21 \pm 1.95$ & - & - & - & - \\
\hline & & & $\mathrm{L}$ & & $15.86 \pm 2.64$ & $8.65 \pm 1.57$ & - & & & \\
\hline \multirow{3}{*}{$\begin{array}{l}\text { The present } \\
\text { study (DAM) }\end{array}$} & & & $\mathrm{L}$ & & $13.73 \pm 1.90$ & $7.37 \pm 1.31$ & $79.05 \pm 13.18$ & & & \\
\hline & & & $\mathrm{R}$ & Exo & $15.32 \pm 1.69$ & $10.20 \pm 2.05$ & $96.60 \pm 17.41$ & & & \\
\hline & & & $\mathrm{L}$ & & $15.87 \pm 1.98$ & $8.68 \pm 1.72$ & $86.65 \pm 14.53$ & & & \\
\hline \multirow[t]{4}{*}{$\begin{array}{l}\text { The present } \\
\text { study }(\mathrm{CT})\end{array}$} & & 20 & $\mathrm{R}$ & Endo & $18.53 \pm 2.20$ & $8.46 \pm 1.46$ & $104.08 \pm 19.83$ & 70 & 20 & 10 \\
\hline & & & $\mathrm{L}$ & & $16.37 \pm 2.59$ & $7.94 \pm 1.99$ & $88.01 \pm 33.64$ & & & \\
\hline & & & $\mathrm{R}$ & Exo & $18.64 \pm 2.62$ & $10.59 \pm 2.02$ & $125.54 \pm 30.43$ & & & \\
\hline & & & $\mathrm{L}$ & & $17.79 \pm 3.14$ & $9.32 \pm 1.79$ & $108.81 \pm 31.13$ & & & \\
\hline
\end{tabular}

R: Right, L: Left, endo: Endocranial, exo: Exocranial.

\section{DISCUSSION}

The results of this study contribute to the knowledge in the literature on the numerical values of VC and NC, including their areas, lengths, and widths from the endocranial to the exocranial orifices with a dynamic perspective aiming to emphasize its three-dimensional characteristic as a canal rather than as a foramen.
The anomalies of JF, including enlargement, stenosis, and hypoplasia, may be associated with plasmacytoma, Apert syndrome, meningioma, Crouzon syndrome, schwannoma, Muenke syndrome, achondroplasia, Saethre-Chotzen syndrome, multiple sclerosis, and glomus jugulare tumors $(5,6,10,20,26)$. For instance, Calandrelli et al. reported that the mean area (range, 32.07-55.30 $\mathrm{mm}^{2}$ ) of JF belonging to 
13 children with achondroplasia was smaller than that in the control group (range, 53.46-97.07 $\mathrm{mm}^{2}$ ) (5). In addition, Papini et al. evaluated 53 patients with multiple sclerosis (mean age, $45 \pm 9$ years) and a number/age/gender-matched control group without multiple sclerosis (20). They found that the mean diameters of the right $(6.3 \pm 1.6 \mathrm{~mm})$ and left $(5.6 \pm 1.3$ $\mathrm{mm}) \mathrm{JF}$ in patients with multiple sclerosis were $10 \%(\mathrm{p}=0.020)$ and $7 \%(\mathrm{p}=0.089)$ smaller than the right $(7 \pm 1.4 \mathrm{~mm})$ and left $(6 \pm 1.3 \mathrm{~mm})$ JF diameters of the control group, respectively. Furthermore, Florisson et al. observed that the diameter of JF in patients with syndromic craniosynostosis diagnosed with Apert, Crouzon/Pfeiffer, Muenke, and Saethre-Chotzen syndromes was significantly smaller than that in patients without syndromic craniosynostosis (10). Considering the difference in the dimensions of JF in patients with severe malformations as reported in previous studies $(5,10,20)$, we believe that a comprehensive radioanatomical perspective incorporating the numerical properties of JF can provide more insights to neurootologists and neurosurgeons during jugular foramen approaches. Moreover, the comparison of data between radiological and anatomical measurements was examined in detail in this study, and statistical differences were detected between the measurments obtained from CT and DAM.

The literature primarily consists of either radiological or anatomical measurements. There is a dearth of investigation performing a comparison between CT and DAM planned to assess the actual dimensions of an anatomical area or structure. Berlis et al. suggested choosing the best scanning position that is appropriate to the manual anatomical measurement plane for the most compatible results (4). Our findings may reveal that the statistical difference between CT and DAM is attributed to the imprecise scanline angle of the radiological assessment compared with the view of anatomical measurement. Therefore, dry skull and cadaver anatomical measurements must be used as an opportunity to choose the best scanning angle coinciding with the assessed anatomical structure. The JF, whose unique position lacking to fit completely to any of the radiological views, including sagittal, coronal, and axial planes perpendicularly, has to be approached with an appropriate angle of scanning.

Considering the current literature, a plexus of the existing reports related to the size of JF is summarized in Table VI. The numerical values obtained in this study are compatible with the range of data reported in the previous studies wherein the widths (range, 3-19 $\mathrm{mm}$ ) and lengths (range, 4.5-29.3 mm) of the right JF and the widths (range, 3--16 mm) and lengths (range, 5-27.4 mm) of the left JF were presented (1-3,9,11$19,21-25)$. However, it is observed that the numerical data related to the right (range, 99.18-913.63 $\mathrm{mm}^{2}$ ) and left (range, 68.93-825.53 $\mathrm{mm}^{2}$ ) areas of JF reported in the literature are distributed over a wide range $(1,2,11,14,15)$. The reason why the numerical data related to the areas of JF are so different can be due to the measurement techniques and the demographic data such as the region, race, and sex $(3,14,15)$. However, as the data reported in the studies on the width and length of JF appear to be more consistent, we believe that the primary reason that triggers this difference in its area is the technique used in the measurements, such as Radinsky formula, Teixeria formula, or automatic field setting of software (27). As shown in Table $\mathrm{VI}$, there are plenty of numerical data on the total size of JF in the literature (1-3,11-19,21-25). However, existing inventory placed on the quantitative analysis of the size of VC and NC appears to be limited (9). Di Chiro et al. measured the endocranial (at a mean $5 \mathrm{~mm}$ for the right side and $4.7 \mathrm{~mm}$ for the left side) and exocranial (at a mean $5 \mathrm{~mm}$ for the right side and $5.1 \mathrm{~mm}$ for the left side) NC width (9). They described that the side predominance stems from the size variations of VC (9). Similar to their study, our findings suggested that both endocranial and exocranial JF size differences stem from the dimension and shape of VC.

On the other hand, our findings related to the side predominance are compatible with those of previous studies, wherein right $>$ left (range, 55\%-75\%), right < left (range, 19.10\%-37.14\%), and right $=$ left (range, 2\%-20\%) were provided (1,9,12-15,17-19,23). There are several theories about why the right side is dominant. In the study of Adams et al. (2), the number of patients of right > left (180 patients), right $<$ left (63 patients), and right = left (33 patients) for the right-handed (276 patients) and the number of patients of right $>$ left (11 patients), right < left (16 patients), and right $=$ left (4 patients) for the left-handed (31 patients) were presented. They suggested that the jugular foramen dominance was significantly associated with the hand preference. This was assumed to be due to excessive muscle development on the dominant side, which triggered an increase in the pressure of the ipsilateral venous system (2). Another reason may stem from the variations of venous outflow such as the superior sagittal sinus, which typically drains into the right transverse sinus (12). The reason for the side predominance may be due to the diameter variations of the sigmoid sinus, the internal jugular vein, and the brachiocephalic vein $(6,9,12,27)$. In the present study, compatible with previous studies (8), the right sigmoid sinus was found to be wider than the left sigmoid sinus.

\section{Limitations}

Although the statistical results show a significant $p$ value, small sample size is the limitation of this study.

\section{CONCLUSION}

The right JF was found to be dominant due to the size of the endocranial and exocranial VC. A statistical difference was found between the data obtained from CT and DAM. Therefore, precise radiological assessment of the JF by an experienced neuroradiologist coinciding with the best scanline angle to the DAM has to be further investigated to standardize the scanning technique for successful surgeries of the skull base.

\section{ACKNOWLEDGEMENT}

The authors thank Professor Arzu Kanik for her contribution to the statistical analysis of the present study. 


\section{REFERENCES}

1. Abhilasha M, Leena R, Sushma KK, Ritu A: Morphological and morphometric study of jugular foramen in western Rajasthan population. IJARR 1:19-24, 2016

2. Adams WM, Jones RL, Chavda SV, Pahor AL: CT assessment of jugular foramen dominance and its association with hand preference. J Laryngol Otol 111:290-292, 1997

3. Ahmed MM, Jeelani M, Tarnum A: Anthropometry: A comparative study of right and left sided foramen ovale, jugular foramen and carotid canal. Int J Sci Stud 3:88-94, 2015

4. Berlis A, Putz R, Schumacher M: Direct and CT measurements of canals and foramina of the skull base. Br J Radiol 65:653661, 1992

5. Calandrelli R, Panfili M, D’Apolito G, Zampino G, Pedicelli A, Pilato F, Colosimo C: Quantitative approach to the posterior cranial fossa and craniocervical junction in asymptomatic children with achondroplasia. Neuroradiology 59:1031-1041, 2017

6. Caldemeyer KS, Mathews VP, Azzarelli B, Smith RR: The jugular foramen: A review of anatomy, masses, and imaging characteristics. Radiographics 17:1123-1139, 1997

7. Cinalli G, Renier D, Sebag G, Sainte-Rose C, Arnaud E, PierreKahn A: Chronic tonsillar herniation in Crouzon's and Apert's syndromes: The role of premature synostosis of the lambdoid suture. J Neurosurg 83:575-582, 1995

8. Das SS, Saluja S, Vasudeva N: Complete morphometric analysis of jugular foramen and its clinical implications. J Craniovertebr Junction Spine 7:257-264, 2016

9. Di Chiro G, Fisher RL, Nelson KB: The jugular foramen. J Neurosurg 21:447-460, 1964

10. Florisson JM, Barmpalios $G$, Lequin $M$, van Veelen $M L$, Bannink N, Hayward RD, Mathijssen IM: Venous hypertension in syndromic and complex craniosynostosis: The abnormal anatomy of the jugular foramen and collaterals. J Craniomaxillofac Surg 43:312-318, 2015

11. Gupta C, Kurian P, Seva KN, Kalthur SG, D’Souza AS: A morphological and morphometric study of jugular foramen in dry skulls with its clinical implications. J Craniovertebr Junction Spine 5:118-121, 2014

12. Hatiboglu MT, Anil A: Structural variations in the jugular foramen of the human skull. J Anat 180:191-196, 1992
13. Hossain SM, Hossain SMM, Banna FAMH: Variations in the structure of the jugular foramen of human skull. BJA 10:45-49, 2012

14. Hussain Saheb S, Mavishetter GF, Thomas ST, Prasanna LC, Muralidhar P: Morphometric study of the jugular foramen in human adult skulls of South India. J Biomed Sci Res 2:240 243, 2010

15. Idowu OE: The jugular foramen-A morphometric study. Folia Morphol (Warsz) 63:419-422, 2004

16. Ishwarkumar S, Naidoo N, Lazarus L, Pillay P, Satyapal KS: An osteometric evaluation of the jugular foramen. Int $\mathrm{J}$ Morphol 33: 251-254, 2015

17. Jain LSR, Kushwah RS: Study of morphometric variations in jugular foramen and jugular fossa of dried adult human skulls. IJCMR 5:6-10, 2018

18. Kumar A, Akhtar MJ, Kumar A: Variations in jugular foramen of human skull. Asian J Med Sci 6:95-98, 2015

19. Navsa N, Kramer B: A quantitative assessment of the jugular foramen. Ann Anat 180:269-273, 1998

20. Papini GDE, Di Leo G, Zanardo M, Fedeli MP, Merli I, Sardanelli $\mathrm{F}$ : Measurement of jugular foramen diameter using MRI in multiple sclerosis patients compared to control subjects. Eur Radiol Exp 1:4, 2017

21. Patel MM, Singel TC: Variations in the structure of the jugular foramen of the human skull in Saurashtra region. J Anat Soc India 56:34-37, 2007

22. Pereira GA, Lopes PT, Santos AM, Krebs WD: Morphometric aspects of the jugular foramen in dry skulls of adult individuals in Southern Brazil. J Morphol Sci 27:3-5, 2010

23. Sturrock RR: Variations in the structure of the jugular foramen of human skull. J Anat 160:227-230, 1988

24. Ukoha UU, Okeke CM, Ukoha C, Obazie IF, Nwankwo HC, Ekezie J: Morphometric study of the jugular foramen in dry Nigerian skulls. Rev Arg de Anat Clin 10:112-119, 2018

25. Vlajkovic S, Vasovic L, Dakovic-Bjelakovic M, Stankovic S, Popovic J, Cukuranovic R: Human bony jugular foramen: Some additional morphological and morphometric features. Med Sci Monit 16:140-146, 2010

26. Vogl TJ, Bisdas S: Differential diagnosis of jugular foramen lesions. Skull Base 19:3-16, 2009

27. Wysocki J, Reymond J, Skarzynski H, Wróbel B: The size of selected human skull foramina in relation to skull capacity. Folia Morphol (Warsz) 65:301-308, 2006 